\title{
Simultaneous progression of oxidative stress and angiogenesis in malignant transformation of Barrett esophagus
}

\author{
Eero I. T. Sihvo, MDa \\ Terhi Ruohtula, $M D^{\mathrm{b}}$ \\ Merja I. Auvinen, $\mathrm{PhD}^{\mathrm{b}}$ \\ Aki Koivistoinen, $M D^{b}$ \\ Ari L. Harjula, MD, PhD ${ }^{a}$ \\ Jarmo A. Salo, MD, $\mathrm{PhD}^{\mathrm{a}}$
}

Background: Oxidative stress and angiogenesis are important elements in the pathogenesis of inflammatory diseases and cancer. Our aim was to evaluate the role of both and of antioxidant capacity in the metaplasia-dysplasia-adenocarcinoma sequence in Barrett epithelium.

Methods: In mucosal specimens from 59 patients grouped as having symptomatic gastroesophageal reflux disease, Barrett epithelium, or adenocarcinoma in the esophagus, plus controls, we measured myeloperoxidase activity, superoxidase dismutase activity, glutathione content, and total aromatic DNA adducts. To evaluate blood vessel densities and angioarchitecture, we used immunohistochemistry and a modified whole-mount technique. Sections were stained with endotheliumspecific markers and smooth muscle cell actin.

Results: The reflux disease-metaplasia-carcinoma sequence revealed progressively increased oxidative stress (increased myeloperoxidase activity), decreased antioxidant capacity (glutathione content), and simultaneous formation of DNA adducts. Pooled data show a negative correlation between glutathione content and DNA adducts $(-0.28 ; P=.05)$. This sequence was also characterized by increased intensity in microvessels and an increasing percentage of immature blood vessels. In addition, the whole-mount technique offered 3-dimensional evidence that the rich

From the Department of Surgery, ${ }^{a}$ Helsinki University Central Hospital, and Department of Biosciences, Helsinki University, ${ }^{\mathrm{b}}$ Helsinki, Finland.

Read at the Eighty-third Annual Meeting of The American Association for Thoracic Surgery, Boston, Mass, May 4-7, 2003.

Received for publication April 25, 2003; revisions requested Aug 6, 2003; revisions received Aug 11, 2003; accepted for publication Aug 19, 2003.

Address for reprints: Jarmo A. Salo, MD, $\mathrm{PhD}$, Department of Cardiothoracic Surgery, Section of General Thoracic and Esophageal Surgery, Helsinki University Central Hospital, PO Box 340, Haartmaninkatu 4, FIN-00290 Helsinki, Finland (E-mail: jarmo.salo@hus.fi).

J Thorac Cardiovasc Surg 2003;126:1952-7

Copyright (C) 2003 by The American Association for Thoracic Surgery

$0022-5223 / 2003 \$ 30.00+0$

doi:10.1016/j.jtcvs.2003.08.014 new vascular bed is highly abnormal, with repeated twists, bends, or turns, even in nonmalignant Barrett esophagus.

Conclusions: Increased oxidative stress, decreased antioxidant capacity, and a negative correlation between glutathione content and DNA adduct formation indicate a link between oxidative stress and malignant transformation of Barrett epithelium. Simultaneously, this transformation acquires angiogenic capacity, strong neovascularization, and abnormal angioarchitecture.

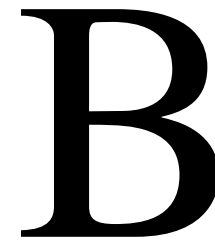

arrett esophagus is a complication of gastroesophageal reflux disease (GERD). This specialized intestinal metaplasia is considered to be a premalignant condition for esophageal adenocarcinoma, which is rapidly increasing in incidence. ${ }^{1-3}$ Although its direct morphological sequence from metaplasia via dysplasia to cancer is recognizable, the exact pathomechanism of this malignant transformation is unknown. ${ }^{4}$ A driving force may, however, be oxidative stress. ${ }^{5,6}$

Oxidative stress stimulates angiogenesis in cultured endothelial cells. ${ }^{7}$ Endothelial cell proliferation and microvascular remodeling occur at an early stage in chronic inflammation, ${ }^{8}$ providing metabolic support for the tissues and allowing 
inflammatory cells to reach the diseased area. In several organs, chronic inflammation has been associated with cancer. ${ }^{9-11}$ For their continuous growth beyond the diffusion limit of oxygen, tumors must recruit new blood vessels, ${ }^{12}$ and such formation of new blood vessels from preexisting ones-angiogenesis-occurs in chronic inflammation and in tumor progression. In tumor cells, oxidative stress has increased the production of angiogenic factors, interleukin-8, and vascular endothelial growth factor. ${ }^{13}$ In the metaplasia-dysplasia-adenocarcinoma sequence in the esophagus, potential factors stimulating angiogenesis are vascular endothelial and fibroblast growth factors. ${ }^{14,15}$ Recently, high vascularization was disclosed in esophageal adenocarcinoma and the adjacent intestinal metaplasia. ${ }^{15,16}$

Potential modulators of angiogenic activity are oxygen free radical scavengers. ${ }^{17,18}$ The glutathione (GSH) redox system and superoxide dismutase (SOD) are each considered to play a major role in the defense mechanism against oxidative stress. ${ }^{19,20}$ SOD catalyzes superoxide to less toxic compounds, and GSH serves as a substrate in reactions in which electrophilic compounds, oxidants, and xenobiotics are detoxified. ${ }^{20}$ GSH content and SOD levels are, in fact, noticeably lower in Barrett epithelium than in normal esophageal mucosa. ${ }^{21,22}$

Because oxidative stress plays a role in the pathogenesis of GERD and in blood vessel growth in tumors, ${ }^{22,23}$ it may be related to the malignant transformation and angiogenesis of Barrett esophagus. This hypothesis was studied in controls and GERD patients with the spectrum of Barrett changes.

\section{Materials and Methods \\ Patients}

This study included 59 white patients (Table 1): 14 had symptomatic reflux disease with pathologic 24-hour $\mathrm{pH}$ measurement $(\mathrm{pH}$ $<4 ; 16.9 \% \pm 9.2 \%$ ), and 15 had Barrett esophagus with histologically observable intestinal metaplasia with goblet cells in the tubular esophagus. All patients with Barrett esophagus had reflux symptoms and a pathologic 24-hour $\mathrm{pH}$ measurement $(\mathrm{pH}<4$; $30.8 \% \pm 20.4 \%$ ). Of the 59 patients, 21 had adenocarcinoma of the distal esophagus or esophagogastric junction. Controls were 9 patients with neither symptoms nor endoscopic evidence of esophageal pathology. No statistically significant age differences existed between the groups (Table 1). The Ethics Committee of Helsinki University Hospital approved this protocol.

\section{Tissue-Sample Collection}

All samples were taken either at endoscopy, with biopsy forceps, or during operation, from the resected specimen. Patients were told to forego any acid-suppressive treatment for 2 weeks before the sampling (proton pump inhibitors, $\mathrm{H}_{2}$-blockers, or others). In Barrett and adenocarcinoma patients, the most evident area macroscopically was sampled. In GERD patients in case of endoscopic normal mucosa and in the control group, samples were taken $5 \mathrm{~cm}$ above the esophagogastric junction. Tissue adjacent to the speci-
TABLE 1. Patient groups

\begin{tabular}{lrc}
\hline Patient group & $\mathbf{n}$ & $\begin{array}{c}\text { Age, y, mean } \pm \text { SD } \\
\text { (range) }\end{array}$ \\
\hline Control & 9 & $50.1 \pm 16.6(25-76)$ \\
Reflux disease & 14 & $52.9 \pm 10.9(27-66)$ \\
Barrett esophagus & 15 & $53.6 \pm 9.2(42-69)$ \\
Adenocarcinoma & 21 & $57.9 \pm 13.4(39-77)$ \\
Total & 59 & $54.3 \pm 12.5(25-77)$ \\
\hline
\end{tabular}

men for histopathologic examination was processed for nonhistological analysis. For analysis of oxidative metabolism and DNA adducts, specimens were immediately frozen and stored at $-70^{\circ} \mathrm{C}$; for analysis of angiogenesis, on the day of collection, only resected specimens were processed to provide enough tissue for the wholemount method. Only 15 surgical samples were thus provided for this part of the study. Because of this, 7 of the 10 Barrett samples were from patients with adenocarcinoma. Of the 13 normal esophageal squamous samples, 3 were obtained from Barrett patients and 10 were from patients with adenocarcinoma.

\section{Methods}

Myeloperoxidase (MP) activity was determined by modification of the method of Suzuki and colleagues. ${ }^{24}$ SOD activity and GSH content were determined by the methods of Laihia and colleagues $^{25}$ and of Saville, ${ }^{26}$ respectively.

To assess overall exposure to DNA-reactive agents, we measured by the ${ }^{32} \mathrm{P}$-postlabeling technique the total aromatic DNA adducts detected in a Bio-Rad Image Analysis System (Bio-Rad Laboratories, Hercules, Calif). ${ }^{27}$ Although the method detects a range of DNA adducts, smoking, nitrosamines, and aromatic hydrocarbons, sources of adducts other than oxidative stress were not evaluated. Average levels of DNA adducts are expressed as adducts $/ 10^{9}$ nucleotides.

Tissue sections of resection specimens were stained with hematoxylin-eosin (Sigma, St Louis, Mo), Alcian blue (BDH Laboratory Supplies Pool, Dorset, United Kingdom), and neutral red (Sigma) to assess tissue histology and to localize Barrett epithelium-specific goblet cells and blood vessels. To quantify blood vessel densities, paraffin-embedded sections were deparaffinized and stained for monoclonal antibody EN4 (which recognizes the endothelium-specific transmembrane protein CD31; Monosan, Uden, the Netherlands). Blood vessels that stained positive for human endothelium were quantified in $200 \times$ magnification microscopic fields (Olympus BX, Tokyo, Japan), and average counts were made of 9 fields rich in vasculature from the mucosa as well as from the periphery of the submucosal tissue.

For 3-dimensional studies, a whole-mount method was adapted from Ryan and associates. ${ }^{28}$ One- to 2-mm-thick whole-mount sections were stained for endothelium-specific markers (PAL-E and EN4) and smooth muscle cell actin (SMA). PAL-E (which recognizes an undefined endothelial antigen present in microvessels, but not in arteries) and EN4 were purchased from Monosan (Immunodiagnostics, Hämeenlinna, Finland). Horseradish peroxidase-conjugated anti-SMA monoclonal antibodies were from DAKO Corporation (Copenhagen, Denmark). Whole-mount sections were viewed and photographed at $10 \times$ magnification (Leica MZFLIII microscope, Solms, Germany). 
TABLE 2. Descriptive statistics with $\boldsymbol{P}$ values by parameter and group

\begin{tabular}{|c|c|c|c|c|}
\hline Parameter & $\begin{array}{c}\text { Control } \\
\text { (co) }\end{array}$ & GERD & $\begin{array}{c}\text { Barrett } \\
\text { (be) }\end{array}$ & $\begin{array}{l}\text { Carcinoma } \\
\text { (ca) }\end{array}$ \\
\hline $\mathrm{n}$ & 9 & 14 & 15 & 21 \\
\hline \multicolumn{5}{|c|}{ Glutathione (gsh) (nmol/mg protein) } \\
\hline $\begin{array}{l}\text { Mean } \pm \text { SD } \\
P \text { value* }\end{array}$ & $2.88 \pm 0.74$ & $\begin{array}{l}1.78 \pm 0.61 \\
.004\end{array}$ & $\begin{array}{l}1.30 \pm 0.27 \\
<.001\end{array}$ & $\begin{array}{l}1.30 \pm 1.30 \\
<.001\end{array}$ \\
\hline$P$ valuet & .004 & & .007 & .007 \\
\hline \multicolumn{5}{|c|}{ Superoxide dismutase (U/mg protein) } \\
\hline Mean $\pm S D$ & $0.122 \pm 0.028$ & $0.097 \pm 0.044$ & $0.222 \pm 0.149$ & $0.236 \pm 0.309$ \\
\hline$P$ value* & & .130 & .042 & .204 \\
\hline$P$ valuet & .130 & & .002 & .037 \\
\hline \multicolumn{5}{|c|}{ Myeloperoxidase (mp) (U/mg protein) } \\
\hline $\begin{array}{l}\text { Mean } \pm S D \\
P \text { value }\end{array}$ & $0.21 \pm 0.23$ & $\begin{array}{l}1.41 \pm 2.01 \\
.244\end{array}$ & $\begin{array}{l}3.87 \pm 2.67 \\
.002\end{array}$ & $\begin{array}{l}2.21 \pm 2.88 \\
<.001\end{array}$ \\
\hline$P$ valuet & .244 & & .016 & .053 \\
\hline \multicolumn{5}{|c|}{ DNA adducts $/ 10^{9}$ nucleotides } \\
\hline $\begin{array}{l}\text { Mean } \pm \text { SD } \\
P \text { value* }\end{array}$ & $0.14 \pm 0.21$ & $\begin{array}{l}11.5 \pm 4.3 \\
<.001\end{array}$ & $\begin{array}{l}15.2 \pm 13.7 \\
.001\end{array}$ & $\begin{array}{l}8.9 \pm 4.6 \\
<.001\end{array}$ \\
\hline$P$ valuet & $<.001$ & & .423 & .068 \\
\hline
\end{tabular}

GERD, Gastroesophageal reflux disease.

${ }^{*} P$ values based on the Mann-Whitney $U$ test (pairwise comparisons, group vs control).

t $P$ values based on the Mann-Whitney $U$ test (pairwise comparisons, group vs GERD).

\section{Statistical Methods}

Mean, minimum, maximum, and SD were provided as descriptive statistics. GSH content, SOD and MP activities, and DNA adducts were compared between the groups (GERD, Barrett metaplasia, cancer, and control) by the Kruskal-Wallis test; pairwise comparisons were performed by the Mann-Whitney $U$ test. Nonparametric methods were applied because of nonnormalities in the data. Associations between each of these variables between groups were assessed with the Spearman correlation coefficient. All $P$ values were based on 2-sided tests. Statistical calculations were performed with SPSS software (SPSS Inc, Chicago, Ill).

\section{Results}

In the GERD-metaplasia-adenocarcinoma sequence, GSH content was progressively lower and MP activity was higher than in controls. Only in Barrett mucosa did SOD activity differ from control activity $(P=.042)$. Concurrently, mean DNA adduct levels were significantly higher than control levels in all 3 groups. Although levels between groups did not differ significantly, the level was highest in Barrett epithelium (Table 2, Figure 1).

In the pooled data, Spearman correlation analyses between GSH contents and DNA adducts showed a negative correlation $(-0.28 ; P<.05)$, but there was no correlation between SOD or MP activity and DNA adduct levels.

Barrett mucosa was characterized by intense infiltration of endothelium-specific protein CD31-positive angiogenic blood vessels (Figure 2,D). Microvessel density doubled $( \pm \mathrm{SD})$ in Barrett epithelium (82.7 $\pm 57.8 ; P=.05)$ and was 2- to 3-fold greater in advanced adenocarcinoma (117.5 \pm $56.7 ; P=.002)$ than in normal esophageal mucosa (43.9 \pm 28.5).
The whole-mount technique showed only a few blood vessels penetrating into normal esophageal mucosa (Figure 2, A). In Barrett epithelium and in related dysplasia and adenocarcinoma, new angiogenic microvessels infiltrated the entire mucosa (Figure 2, $B$ and $D$ ). The angioarchitecture within Barrett epithelium featured new microvessels that were very small and deformed, containing tortuousities, corkscrew structures, blind ends, and abnormal branching (Figure 2, B). In paraffin sections, an increasing percentage of vessels were devoid of SMA in Barrett epithelium (5\%), dysplasia (25\%), and adenocarcinoma (40\%).

\section{Discussion}

Simultaneous formation of DNA adducts, increased oxidative stress (increased MP activity), decreased antioxidant capacity (reduced GSH content), and angiogenesis in the GERD-metaplasia-adenocarcinoma sequence of Barrett esophagus indicated the important role played by oxidative stress in the pathogenesis and malignant transformation of Barrett epithelium. In studies measuring free radicals by means of chemiluminescence assay and either lipid peroxidation or MP activity in patients with reflux esophagitis or Barrett epithelium, GERD has been shown to increase the production of oxygen free radicals in the esophageal mucosa. $^{22,23}$ In rats, a novel antioxidant (DA-9601) reduced in a dose-dependent manner reflux-related esophageal mucosal damage and lipid peroxidation. ${ }^{29}$ Our study supports these findings, and, in addition, the increase in DNA adducts simultaneously with oxidative stress in complicated GERD strengthens the credibility of a role for gastroesophageal reflux in the pathogenesis of esophageal adenocarcinoma. 


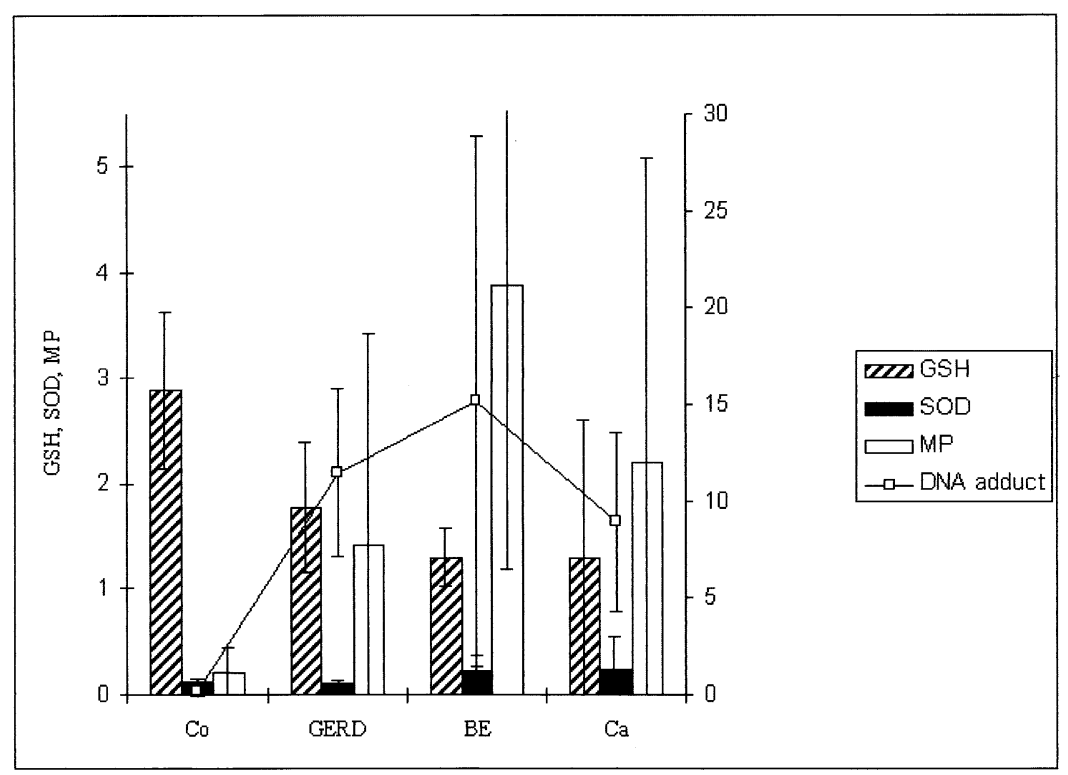

Figure 1. Glutathione (GSH), superoxide dismutase (SOD), and myeloperoxidase (MP) in normal esophageal mucosa (Co), GERD, Barrett epithelium (BE), and adenocarcinoma of the distal esophagus/esophagogastric junction (Ca). SOD and MP are expressed as units per milligram of protein; GSH is expressed as nanomoles per milligram of protein.

An epidemiological association also exists between a higher intake of antioxidants and a decreased risk for esophageal adenocarcinoma. ${ }^{30}$ Oxidative stress can therefore be considered one of the important driving forces for such carcinogenesis.

Accelerated angiogenesis, assessed by higher microvessel density in microscopic fields, appears in Barrett epithelium and esophageal adenocarcinoma. ${ }^{15,16,31}$ In this study, microvessel density was doubled in Barrett epithelium and was 2- to 3-fold higher in advanced adenocarcinoma than in normal esophageal mucosa. Furthermore, the whole-mount technique provided 3-dimensional evidence that during the early stage of tumor development in Barrett epithelium, the rich, new vascular bed is already highly abnormal. Malignant transformation of Barrett epithelium must, therefore, be angiogenesis dependent. Simultaneous angiogenesis and increases of MP activity in the GERD-metaplasia-adenocarcinoma sequence of Barrett esophagus suggest that oxidative stress is a component of a pathway that leads to the onset and process of angiogenesis in the esophageal mucosa. This study provides, however, no direct evidence to link oxidative stress with angiogenesis.

An onset and process of angiogenesis requires a change in the local equilibrium between proangiogenic and antiangiogenic factors. ${ }^{32,33}$ Oxidative stress, after causing nonlethal cell injury to cells, may initiate a cascade of signal transduction that leads to a tissue-repair process and to angiogenesis. ${ }^{34}$ Endothelial and inflammatory cells release angiogenesis activators, such as vascular endothelial growth factor, angiopoietin-1, fibroblast growth factor, and transforming growth factor, in abundance. ${ }^{12}$ Among these potential proangiogenic factors, matrix metalloproteinase, vascular endothelial growth factor, transforming growth factor, and fibroblast growth factor have been discovered in the metaplasia-dysplasia-adenocarcinoma sequence of Barrett esophagus. ${ }^{14,35,36}$

In an animal model, inhibition of oral carcinogenesis by GSH was related to inhibition of tumor angiogenesis. ${ }^{17}$ In this study, DNA adducts were already higher and GSH levels lower in GERD than in controls, indicating the early role of oxidative stress in reflux-related esophageal mucosal damage. With further suppression of antioxidant capacity (GSH) and with increased MP activity in esophagitis and in Barrett epithelium, the mucosa is exposed to amplified oxidative stress; a low content of GSH in Barrett epithelium has indeed been evident. ${ }^{21}$ DNA adducts were highest during carcinogenesis in metaplastic mucosa-as seen in preneoplastic colonic polyps and in tumor-adjacent pancreatic tissue $^{37,38}$ — and not in the final stage of cancer. This study's negative correlation between GSH content and DNA adduct formation indicates that the low antioxidant capacity of the esophageal mucosa leads to an increase in DNA adduct formation and risk for carcinogenesis. At the same time, this GERD-metaplasia-adenocarcinoma sequence was characterized by increased frequency of highly abnormal microvessels. Hence, reflux-related oxidative stress seems to deplete GSH and enhance cellular sensitivity to various agents and the risk for angiogenesis. 


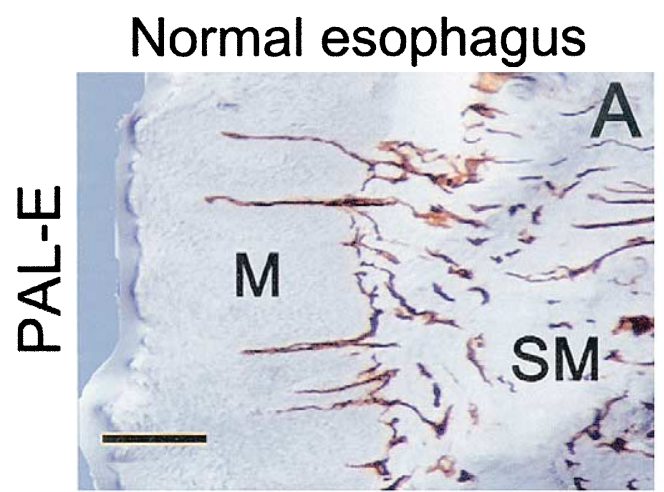

\section{Barrett's epithelium}
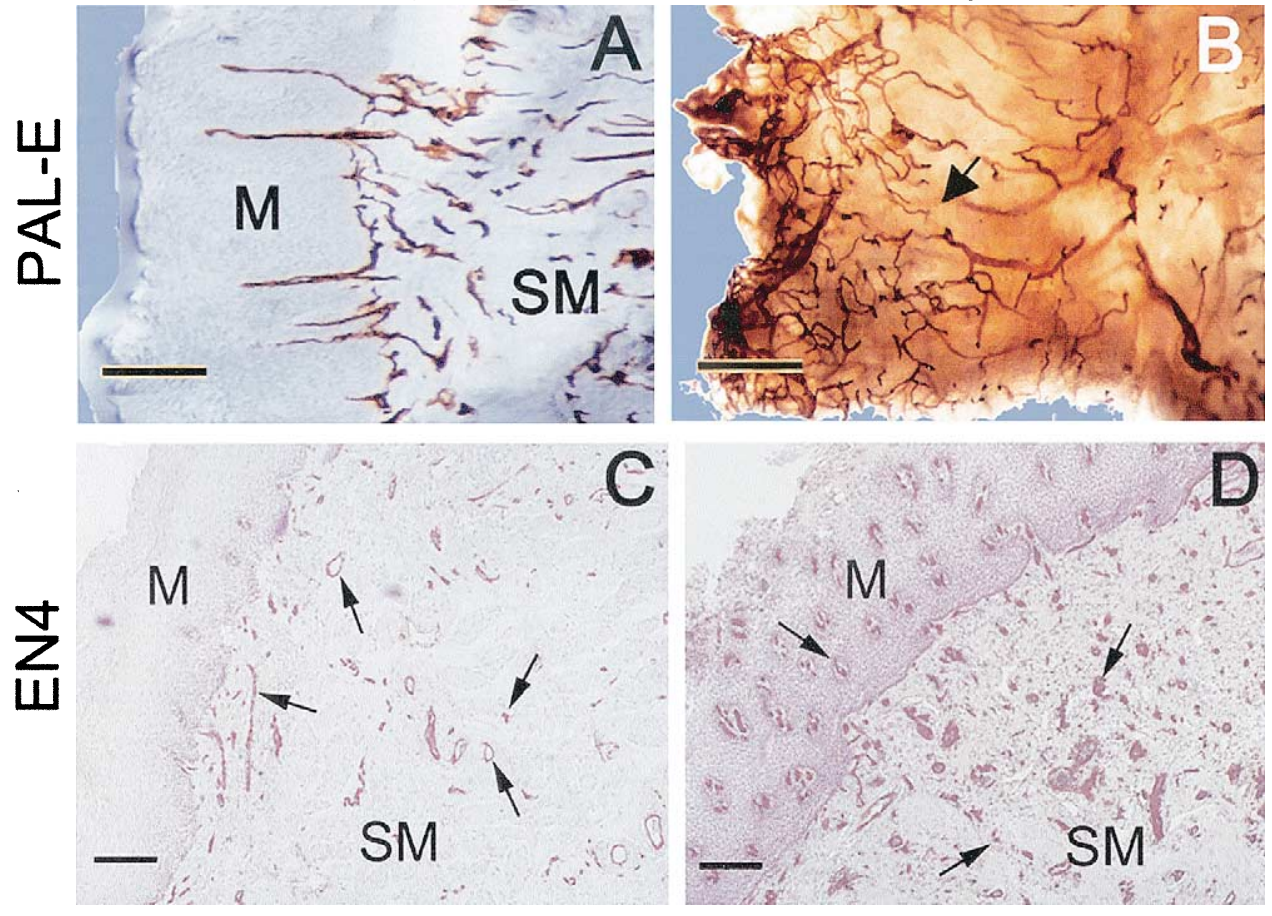

Figure 2. Barrett epithelium is neovascularized. Whole-mount ( $A$ and $B$ ) and paraffin (C and D) sections from normal esophagus and Barrett epithelium stained with antibodies against undefined vascular endothelial marker PAL-E (A and B) or hematoxylin and EN4 (C and D) are shown. The endothelium-specific marker monoclonal antibodies EN4 and PAL-E stain capillaries and microvessels both in mucosa (M) and submucosa (SM). Bloodvessel architecture of the normal esophagus (A) is distorted by new, netlike blood vessel ingrowth in Barrett epithelium (B). Note the strong increase in density of new blood vessels penetrating the mucosa adjacent to the Barrett epithelium (arrows in panel D) in comparison to that of the normal esophageal mucosa (C). Scale bars: 20 $\mu \mathrm{m}$ in panels $A$ and $B ; 50 \mu \mathrm{m}$ in panels $C$ and $D$.

In our study, the total activity of SOD was increased in Barrett mucosa and in adenocarcinoma. Tissue levels of SOD in Barrett mucosa decrease when associated with severe reflux esophagitis but increase with mild esophagitis. ${ }^{22}$ The inflammatory cytokines are able to induce SOD protein expression to increase the ability of cells to confront oxidative stress. ${ }^{39}$ In mice, overexpression of copper/zinc SOD induced angiogenesis. ${ }^{18}$ Although this seems to be a physiologic mechanism to initiate tissue repair, unbalanced overexpression of SOD could place the metaplastic and carcinoma cells under oxidative stress by increasing intracellular $\mathrm{H}_{2} \mathrm{O}_{2}{ }^{40}$ In the Fenton reaction, $\mathrm{H}_{2} \mathrm{O}_{2}$ is converted to highly reactive hydroxyl radicals. In gastric cancer and in esophageal squamous cell cancer, manganese SOD was increased and copper/zinc SOD was decreased, ${ }^{41}$ suggesting that in specific subtypes of SOD, total SOD activity may not reveal significant changes. Further studies are needed to determine the exact contribution of changes in the activities of SOD subtypes and angiogenesis in the GERD-metaplasia-dysplasia-adenocarcinoma sequence of Barrett esophagus.
All these results, taken together, suggest an interesting functional interplay among oxidative stress, radical scavengers, and neovascularization in Barrett mucosa.

We express our gratitude for the statistical analysis performed by Juha Akkila and for the skillful technical and secretarial assistance of Yvonne Sundström.

\section{References}

1. Lagergren J, Bergström R, Lindgren A, Nyren O. Symptomatic gastroesophageal reflux as a risk factor for esophageal adenocarcinoma. N Engl J Med. 1999;340:825-31.

2. Blot WJ, Deveasa SS, Kneller RW, Fraumeni JF Jr. Rising incidence of adenocarcinoma of the esophagus and gastric cardia. JAMA. 1991; 265:1287-9.

3. Sihvo EIT, Salminen JT, Rämö OJ, Salo JA. The epidemiology of oesophageal adenocarcinoma: has the cancer of gastric cardia an influence on the rising incidence of oesophageal adenocarcinoma? Scand J Gastroenterol. 2000;35:1082-6.

4. Levine DS. Management of dysplasia in the columnar-lined esophagus. Gastroenterol Clin North Am. 1997;26:613-34.

5. Chen X, Yang CY. Esophageal adenocarcinoma: a review and perspectives on the mechanism of carcinogenesis and chemoprevention. Carcinogenesis. 2001;22:1119-29. 
6. Farhadi A, Fields J, Banan A, Keshavarzian A. Reactive oxygen species: are they involved in the pathogenesis of GERD, Barrett's esophagus, and the latter's progression toward esophageal cancer? Am J Gastroenterol. 2002;97:22-6.

7. Yasuda M, Ohzeki Y, Shimizu S, Naito S, Ohtsuru A, Yamamoto T, et al. Stimulation of in vitro angiogenesis by hydrogen peroxide and the relation with ETS-1 in endothelial cells. Life Sci. 1999;64:249-58.

8. Ezaki T, Baluk P, Thurston G, La Barbara A, Woo C, McDonald DM. Time course of endothelial cell proliferation and microvascular remodeling in chronic inflammation. Am J Pathol. 2001;158:2043-55.

9. Collins RH, Feldman M, Fordtran JS. Colon cancer, dysplasia, and surveillance in patients with ulcerative colitis: a critical review. $N$ Engl J Med. 1987;316:1654-8.

10. Shimoda R, Nagashima M, Sakamoto M, Yamaguchi N, Hirohashi S, Yokota J, et al. Increased formation of oxidative DNA damage, 8-hydroxydeoxyguanosine, in human livers with chronic hepatitis. Cancer Res. 1994;54:3171-2.

11. Holzinger F, Z'graggen K, Büchler MW. Mechanisms of biliary carcinogenesis: a pathogenetic multi-stage cascade towards cholangiocarcinoma. Ann Oncol. 1999;10(suppl 4):S122-6.

12. Carmeliet P, Jain R. Angiogenesis in cancer and other diseases. $\mathrm{Na}$ ture. 2000;407:249-57.

13. Brown NS, Jones A, Fujiyama C, Harris AL, Bicknell R. Thymidine phosphorylase induces carcinoma cell oxidative stress and promotes secretion of angiogenic factors. Cancer Res. 2000;60:6298-302.

14. Soslow RA, Ying L, Altorki NK. Expression of acidic fibroblast growth factor in Barrett's esophagus and associated esophageal adenocarcinoma. J Thorac Cardiovasc Surg. 1997;114:838-43.

15. Couvelard A, Paraf F, Gratio V, Scoazec JY, Henin D, Degott C, et al. Angiogenesis in the neoplastic sequence of Barrett's oesophagus. Correlation with VEGF expression. J Pathol. 2000;192:14-8.

16. Millikan KW, Mall JW, Myers JA, Hollinger EF, Doolas A, Saclarides TJ. Do angiogenesis and growth factor expression predict prognosis of esophageal cancer? Am Surg. 2000;66:401-5.

17. Schwartz JL, Shklar G. Glutathione inhibits experimental oral carcinogenesis, p53 expression, and angiogenesis. Nutr Cancer. 1996;26: 229-36.

18. Marikovsky M, Nevo N, Vadai E, Harris-Cerruti C. Cu/Zn superoxide dismutase plays a role in angiogenesis. Int J Cancer. 2002;97:34-41.

19. Ogino K, Oka S, Okazaki Y, Takemoto T. Gastric mucosal protection and superoxide dismutase. J Clin Gastroenterol. 1988;10(suppl 1): S129-32.

20. Hayes JD, McLellan LI. Glutathione and glutathione-dependent enzymes represent a co-ordinately regulated defence against oxidative stress. Free Radic Res. 1999;31:273-300.

21. Peters WHM, Roelofs HMJ, Hectors MPC, Nagengast FM, Jansen JB. Glutathione and glutathione S-transferases in Barrett's epithelium. Br J Cancer. 1993;67:1413-7.

22. Wetscher GJ, Hinder RA, Bagchi D, Hinder PR, Bagchi M, Perdikis G, et al. Reflux esophagitis in humans is mediated by oxygen-derived free radicals. Am J Surg. 1995;170:552-6.

23. Olyaee M, Sontag S, Salman W, Schnell T, Mobarhan S, Eiznhamer D, et al. Mucosal reactive oxygen species production in oesophagitis and Barrett's oesophagus. Gut. 1995;37:168-73.

24. Suzuki K, Ota H, Sasagawa S, Sakatani T, Fujikura T. Assay method for myeloperoxidase in human polymorphonuclear leukocytes. Anal Biochem. 1983;132:345-52.

25. Laihia JK, Jansen CT, Ahotupa M. Lucigenin and linoleate enhanced chemiluminescent assay for superoxide dismutase activity. Free Radic Biol Med. 1993;14:457-61.

26. Saville B. A scheme for the colorimetric determination of microgram amounts of thiols. Analyst. 1985;83:670-2.
27. Gupta RC. Non-random binding of the carcinogen $N$-hydroxy-2acetylaminofluorene to repetitive sequences of rat liver DNA in vivo. Proc Natl Acad Sci U S A. 1984;81:6943-7.

28. Ryan HE, Lo J, Johnsson RS. HIF-alpha is required for solid tumor formation and embryonic vascularization. EMBO J. 1998;17:3005-15.

29. Oh TY, Lee JS, Ahn BO, Cho H, Kim WB, Kim YB, et al. Oxidative damages are critical in pathogenesis of reflux esophagitis: implication of antioxidants in its treatment. Free Radic Biol Med. 2001;30:905-15.

30. Terry P, Lagergren J, Ye W, Nyren O, Wolk A. Antioxidants and cancers of the esophagus and gastric cardia. Int J Cancer. 2000;87: 750-4.

31. Torres C, Turner JR, Wang HH, Richards W, Sugarbaker D, Shahsafaei A, et al. Pathologic prognostic factors in Barrett's-associated adenocarcinoma: a follow-up study of 96 patients. Cancer. 1999;85: 520-8.

32. Liotta LA, Steeg PS, Stetler-Stevenson WG. Cancer metastasis and angiogenesis: an imbalance of positive and negative regulation. Cell. 1991;64:327-36.

33. Hanahan D, Folkman J. Patterns and emerging mechanisms of the angiogenic switch during tumorigenesis. Cell. 1996;86:353-64.

34. Maulik N, Das DK. Redox signaling in vascular angiogenesis. Free Radic Biol Med. 2002;33:1047-60.

35. Triadafilopoulo G, Kumble S. Transforming growth factor beta one (TGFb1) expression is enhanced in gastroesophageal reflux disease, Barrett's esophagus, and esophageal adenocarcinoma [abstract]. Gastroenterology. 1996;110:A1126.

36. Salmela MT, Karjalainen-Lindsber ML, Puolakkainen P, SaarialhoKere U. Upregulation and differential expression of matrilysin (MM-7) and metalloelastase (MMP-12) and their inhibitors TIMP-1 and TIMP-3 in Barrett's oesophageal adenocarcinoma. $\mathrm{Br} J$ Surg. 2001;85:383-92.

37. Wang M, Abbruzzese JL, Friess H, Hittelman WN, Evans DB, Abbruzzese MC, et al. DNA adducts in human pancreatic tissues and their potential role in carcinogenesis. Cancer Res. 1998;58:38-41.

38. Schmid K, Nair J, Winde G, Velic I, Bartsch H. Increased levels of promutagenic etheno-DNA adducts in colonic polyps of FAP patients. Int J Cancer. 2000;87:1-4.

39. Harris CA, Derbin KS, Hunte-McDonough B, Krauss MR, Chen KT, Smith DM, et al. Manganese superoxide dismutase is induced by IFN- $\gamma$ in multiple cell lines. Synergistic induction by IFN- $\gamma$ tumor necrosis factor or IL-1. J Immunol. 1991;147:149-54.

40. Dreher D, Junod AF. Role of oxygen free radicals in cancer development. Eur J Cancer. 1996;32A:30-8.

41. Janssen AM, Bosman CB, van Duijn W, Oostendorp-van de Ruit MM, Kubben FJ, Griffioen G, et al. Superoxide dismutases in gastric and esophageal cancer and the prognostic impact in gastric cancer. Clin Cancer Res. 2000;6:3183-92.

\section{Discussion}

Dr Steven J. Mentzer (Boston, Mass). I have 1 question. In the sense that to implicate myeloperoxidase and oxidative stress and some of the angiogenic factors in carcinogenesis you imply a cause and effect, isn't it possible that you can have inflammation that would be associated with these secondary effects that really has no causal relationship to adenocarcinoma of the esophagus?

Dr Sihvo. Myeloperoxidase is shown to increase oxidative stress by generating highly reactive species from hydrogen peroxide. So we think that this shows the increased oxidative stress in these steps. 